\section{Expedição literária pela Amazônia}

Por José Augusto Drummond

Doutor em Land Resources pela Universidade de Wisconsin, USA. Professor Associado do Centro de Desenvolvimento Sustentável, Universidade de Brasília

(jaldrummond@uol.com.br)

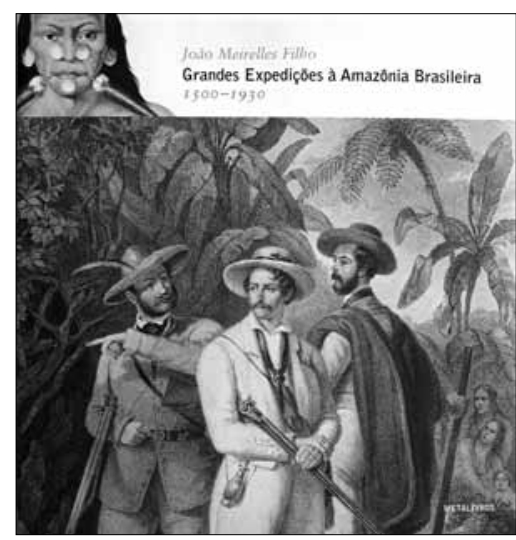

MEIRELLES FILHO, João. Grandes Expedições à Amazônia Brasileira, 1500-1930. São

Paulo: Metalivros, 2009. 241 p.: il. ISBN 978-85-85371-78-4.

Este livro de Meirelles é capaz de abalar, mesmo entre os mais céticos, a noção de que os brasileiros não se esforçam para conhecer a Amazônia, mais da metade da qual pertence ao território do Brasil. É verdade que a atenção maior dada à região nas últimas décadas originou-se em boa parte fora do país, incentivada por estudos, relatos e preocupações de não-brasileiros. De resto, o mesmo aconteceu no passado mais distante, conforme registrado pela própria obra resenhada, pois grande parte das expedições abordadas teve iniciativa, apoio e participantes estrangeiros. No entanto, temos há algum tempo uma massa crítica instalada no país, dentro e fora da região amazônica, dotada da capacidade de estudar, conhecer e divulgar as suas singularidades e os seus significados em escala nacional, continental e global.

Resultado de um longo e abrangente trabalho de pesquisa e de um admirável esforço de síntese de escrita, este livro exemplifica essa capacidade. Foi composto por uma grande equipe de pesquisadores, consultores, tradutores, revisores, diagramadores, designers e técnicos em reprodução de imagens, trabalhando numa empreitada de longa duração. Embora seja principalmente uma obra de divulgação para um público ampliado, a alta qualidade dos textos e das ilustrações e o rigor da documentação das informações fazem dela uma rica fonte para estudos acadêmicos, monográficos e técnicos. Ela sobressairia mesmo se fosse apenas uma obra de divulgação, pela seriedade, pelo capricho e pela resolução impecável.

João Meirelles é escritor e ativista ambiental (dirigente do Instituto Peabiru), envolvido com diversas instituições do Terceiro Setor e participante de projetos de proteção de áreas naturais, dentro e fora da Amazônia. É autor de "O Livro de Ouro da Amazônia" (Ediouro, 2004). É o responsável pelo texto deste novo livro, que, com a ajuda de riquíssimas ilustrações, narra e costura entre si 42 expedições selecionadas que percorreram diferentes partes da Amazônia brasileira entre 1500 e 1930. Este amplo período é delimitado no seu início pelas primeiras viagens periféricas de navegadores europeus em torno da foz do rio Amazonas e, no seu final, pelas últimas expedições basicamente terrestres de Cândido Rondon até o coração continental da Amazônia.

Escolher essas 42 expedições, deixando de fora cerca de 30 outras, deve ter sido uma das tarefas mais difíceis do autor na montagem desta publicação, mas o seu esforço de síntese funcionou: permitiu que o livro ficasse dentro de dimensões razoáveis para o tipo de obra que ele pretendia fazer - um livro de textos, fartamente ilustrado e com o adicional de apresentar uma alta qualidade de impressão. Pode-se esperar, com fundamentadas razões, que a obra aqui resenhada vá merecer pelo menos um segundo volume, que inclua as três dezenas de expedições que, embora registradas e estudadas, ficaram de fora. Para dar a dimensão do contexto ainda maior de expedições na região amazônica, Meirelles teve o cuidado de listar, em breves verbetes que compõem um anexo, outras 525 viagens que percorreram trechos da Amazônia, muitas em territórios dos demais países que compartilham a Grande Amazônia com o Brasil. A amostra de expedições analisadas por Meirelles pode até ser considerada pequena em face 
desse universo enorme, mas a obra é de peso, pois parece ser única, pela sua abrangência e pela sua concepção.

O formato adotado na obra merece ser comentado, pois é sistemático e eficaz. Cada expedição analisada recebe um texto padronizado, acompanhado por uma programação gráfica que combina beleza e funcionalidade. O texto é distribuído por quatro colunas em cada página, com inserções de ilustrações que variam em tamanho, forma, natureza e cores - mapas, fotografias, gravuras e pinturas (com paisagens, animais, plantas), roteiros etc. Muitas ilustrações são de página inteira. Todos os textos contêm as mesmas seções - contexto, líder, colaboradores, percurso, obra (textos ou outros materiais produzidos pelos expedicionários), principais contribuições (literárias, científicas, econômicas, geopolíticas, etnográficas etc.) e as notas bibliográficas. As duas primeiras páginas referentes a cada expedição trazem, ao alto, informações adicionais e sintéticas sobre duração, financiadores e percursos. Cada ilustração é acompanhada da identificação de autores, das datas e da sua fonte original - livros, coleções de museus e arquivos, acervos científicos, acervos particulares, álbuns de exposições e muitas outras.

O autor explica brevemente, na introdução, porque incluiu alguns viajantes e excluiu outros. Ressalta que o critério principal foi o de incluir aqueles que "empresta[m] um novo olhar, nova perspectiva sobre a região, a partir de [suas] andanças" (p. 17). Ele buscou evitar redundâncias, fazendo variar as particularidades individuais e as missões dos expedicionários escolhidos - bandeirantes, clérigos, missionários, militares, demarcadores de fronteiras, cientistas (etnólogos, arqueólogos, botânicos, zoólogos, geólogos, linguistas), pintores etc. Fica patente que era impossível incluir todos. No entanto, em face da relevância dos aspectos humanos e naturais da região e da própria abundância de expedições e de documentação conexa, nenhum critério de seleção agradará a tantos leitores quanto a esperança de que Meirelles e a sua equipe produzam um ou mais volumes que incluam as expedições que a obra resenhada foi obrigada a excluir.
Dada a homogeneidade dos 42 relatos, é difícil destacar qualquer um deles. Algumas expedições e alguns expedicionários chamam a atenção exatamente por serem mais conhecidos - Pedro Teixeira, Condamine, Alexandre Rodrigues Ferreira, Spix e Martius, Langsdorff, Wallace, Agassiz e Rondon. Em outros relatos há ilustrações de qualidade excepcional que seduzem o leitor predisposto a usufruir de um livro tão ricamente ilustrado. As cristalinas fotos das expedições de Rondon, as suaves borboletas pintadas por Bates e as densas gravuras de Orton são exemplos disso.

Apenas para enriquecer a apreciação da obra, destaco o capítulo dedicado a Cândido Mariano da Silva Rondon (1865-1958), militar brasileiro, já que brasileiros propriamente ditos (como Couto de Magalhães, Euclides da Cunha e Mário de Andrade) formam uma pequena minoria dos líderes das expedições selecionadas. Além disso, Meirelles destaca que Rondon, entre todos os expedicionários estudados, foi o "grande viajante", ou seja, aquele que percorreu as maiores distâncias, acumuladas ao longo de quatro décadas de excursões por áreas hoje incorporadas aos estados de Mato Grosso do Sul, Mato Grosso, Rondônia, Acre, Amazonas, Pará, Goiás, Tocantins, Amapá e Roraima.

Meirelles registra outros feitos notáveis de Rondon. As suas numerosas expedições geraram abundantes 140 relatórios (mais de 20.000 páginas) e outros materiais impressos. Mesmo exercitando a sua notável capacidade de síntese, Meirelles se viu obrigado a dividir as numerosas expedições de Rondon em 14 ciclos, cada um dos quais abrange muitas viagens. Essas expedições foram também as maiores coletoras de materiais científicos e etnográficos depositados no Museu Nacional do Rio de Janeiro e em outras instituições. É relevante notar também que Rondon cumpriu uma grande variedade de missões em sua longa carreira de viajante - construtor de picadas e de linhas e estações telegráficas; produtor de documentação cartográfica; fornecedor de materiais para estudos científicos; demarcador de fronteiras internacionais; pacificador e protetor de indígenas; fundador e primeiro diretor do Serviço de Proteção ao Índio. Rondon exerceu

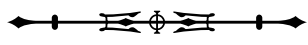


até o curioso papel composto de líder expedicionário e guia do ex-presidente dos EUA, Theodore Roosevelt, que se incorporou como convidado do governo brasileiro a uma de suas mais difíceis expedições (ao rio da Dúvida). Roosevelt quase morreu nessa expedição e escreveu sobre ela um ótimo relato de viagem, com fartos elogios a Rondon. Dessa forma, Meirelles ajuda a recuperar a memória deste grande brasileiro que foi Rondon.

Resta dizer que o texto não tem uma 'tese' central a argumentar ou provar, conforme destaca o próprio autor na sua introdução. No entanto, seria errado dizer que o livro é meramente descritivo, pois nenhum autor, ao reunir, refletir sobre, selecionar e usar tantos materiais sobre uma região de tão grande complexidade poderia se comportar como um narrador descomprometido. Com efeito, o autor manifesta as suas preocupações e a sua atenção para com questões como a dizimação física, territorial e cultural dos povos indígenas da região, a repartição da região entre a soberania de vários países, a escassez de instituições científicas e de cientistas brasileiros instalados na e estudiosos da região, o papel do avanço das fronteiras agrícolas, pecuárias, mineradoras e madeireiras contemporâneas na degradação do bioma Amazônia, entre outras. No entanto, a alma do livro é a recuperação da memória e dos feitos dos expedicionários e das expedições.

Meirelles produziu um livro vitorioso que merece ser lido pelo público mais variado e amplo possível, desde estudiosos da Amazônia a cidadãos comuns, brasileiros da região e de fora dela e estrangeiros que se interessam por ela. Conforme sugerido acima, fica a esperança de que ele e sua equipe produzam um ou mais novos volumes que tratem de outros expedicionários e outras expedições, para assim enriquecer o acervo de produções nacionais sobre a Amazônia. 